\title{
Reduced Surgical Site Infection Rates Following Spine Surgery Using an Enhanced Prophylaxis Protocol
}

Alexa M. Dessy ${ }^{1}$, Frank J. Yuk ${ }^{1}$, Akbar Y. Maniya ${ }^{2}$, James G. Connolly ${ }^{3}$, John T. Nathanson ${ }^{1}$, Jonathan J. Rasouli ${ }^{1}$, Tanvir F. Choudhri ${ }^{4}$

1. Icahn School of Medicine at Mount Sinai, Mount Sinai Medical Center 2. Surgery, Montefiore Medical Center, New York, USA 3. Mount Sinai Medical Center 4. Neurosurgery, The Icahn School of Medicine at Mount Sinai, New York, USA

$\square$ Corresponding author: Akbar Y. Maniya, akbar.maniya@icahn.mssm.edu Disclosures can be found in Additional Information at the end of the article

\section{Abstract}

\section{Background}

Postoperative surgical site infection (SSI) is a common complication after spine surgery. Reduction of SSI has many benefits including, but not limited to, the reduced length of stay, readmission rates, and morbidity and mortality.

\section{Objective}

To determine whether an enhanced antibiotic prophylaxis reduced the rate of surgical site infections in spine surgery.

\section{Methods}

This is a retrospective observation study which analyzed the incidence of postoperative SSI following a consecutive series of 1,486 cervical, thoracic and lumbar spine operations performed at a single institution by the senior author between the dates of October 2001 to March 2014. Patients with surgeries between October 2001 and November 2005 received a standard institutional antibiotic prophylaxis. Patients between December 2005 and March 2014 underwent an enhanced antibiotic protocol.

\section{Results}

Received 12/20/2016 Review began 12/30/2016 Review ended 03/29/2017 Published 04/06/2017

\section{(c) Copyright 2017}

Dessy et al. This is an open access article distributed under the terms of the Creative Commons Attribution License CC-BY 3.0., which permits unrestricted use, distribution, and reproduction in any medium, provided the original author and source are credited.
A total of nine cases met the criteria for SSI. All nine cases were recorded during the initial time period when the standard institutional prophylaxis was used. Further, these cases were only observed under posterior operative approaches. No further cases of SSI were observed after the institution of the enhanced antibiotic prophylaxis $(\mathrm{p}<0.0001)$. This was statistically significant in the cervical and lumbar regions ( $p<0.0042$ and $p<0.0119$, respectively).

\section{Conclusions}

Although difficult to predict the incidence of SSI, this study found that the use of an enhanced antibiotic prophylaxis protocol significantly reduced one surgeon's overall rates of surgical site infections after spine surgery. 
Categories: Infectious Disease, Neurosurgery, Orthopedics

Keywords: surgical site infection, spine surgery, infection, antibiotic prophylaxis

\section{Introduction}

Postoperative surgical site infection (SSI) is a relatively common complication after spine surgery. The incidence of postoperative infection after spinal surgery has been reported between $0.1 \%$ and to $6.7 \%$. Reported rates of SSI vary among different patient populations, procedures, surgeons, and surgical approaches [1-8]. SSI can result in increased morbidity and mortality, the length of hospital stay, increased readmission rate and hospital costs, and postoperative pain. It can also result in and the requirement for an additional surgical procedure, including wound debridement and replacement of hardware [9-13].

Each incidence of SSI can increase the cost of care up to four times the cost of the initial spine surgery [14-17]. Costs are reported to range between $\$ 15,800$ and $\$ 43,900$ per SSI $[1,18]$. Therefore, efforts to reduce SSI are paramount. In addition, conflicting reports have been published regarding the ideal timing of surgical antimicrobial prophylaxis and the most effective preoperative skin antisepsis [19]. As such, this retrospective review evaluates the incidence of postoperative SSI following spine surgery performed by a single neurosurgeon at a single institution before and after implementation of an enhanced modified prophylaxis protocol.

\section{Materials And Methods}

This retrospective study analyzed the incidence of postoperative SSI following a consecutive series of 1,486 cervical, thoracic, and lumbar spine operations performed at a single institution by the senior author in two patient populations that received either the standard prophylaxis protocol or the enhanced prophylaxis protocol between October 2001 and March 2014. From October 2001 until November 2005, patients undergoing spine surgery received the standard institutional protocol. From December 2005 until March 2014, patients undergoing spine surgery received the enhanced protocol (Table 1). Surgical site infections were recorded and defined as per standard of the centers for disease control and prevention (CDC) definitions [20] (Table 2). Inclusion criteria were adult patients undergoing elective cervical, thoracic, or lumbar surgical operations (either primary or revision) by the senior author and the stated date restrictions. Exclusion criteria consisted of only those patients with preexisting infections. Patients were not excluded on the basis of medical comorbidities (diabetes, congestive heart failure (CHF), low serum protein, etc.) or procedure length. 


\section{Cureus}

\begin{tabular}{|c|c|c|}
\hline Indication & Standard Protocol & Enhanced Protocol \\
\hline $\begin{array}{l}\text { Patient Skin } \\
\text { Preparation }\end{array}$ & $\begin{array}{l}\text { Standard betadine/iodine } \\
\text { scrub/paint. Select use of alcohol } \\
\text { pads }\end{array}$ & $\begin{array}{l}\text { Three betadine scrub brushes Six alcohol wipes on incision } \\
\text { area }^{1} \text { Betadine ointment application }{ }^{2}\end{array}$ \\
\hline $\begin{array}{l}\text { Alcohol Pad } \\
\text { Preparation }\end{array}$ & Select use & Regular use \\
\hline $\begin{array}{l}\text { Patient Prep } \\
\text { Performance }\end{array}$ & Select attending performance & Regular attending performance \\
\hline $\begin{array}{l}\text { Pulse Irrigator } \\
\text { (Saline with } \\
\text { Bacitracin) }\end{array}$ & Select use & Regular use for posterior instrumentation \\
\hline Surgical Drains ${ }^{3}$ & Select use & Regular use ${ }^{4}$ \\
\hline $\begin{array}{l}\text { Prophylactic } \\
\text { Antibiotic } \\
\text { Coverage (unless } \\
\text { allergic) }\end{array}$ & $\begin{array}{l}\text { IV Cefuroxime for } 24 \text { hours Select } \\
\text { use of IV Vancomycin (in case of } \\
\text { cephalosporin allergy only) }\end{array}$ & $\begin{array}{l}\text { Regular use for the posterior instrumentation: IV Cefuroxime for } \\
24 \text { hoursIV Vancomycin until drain removal Non- } \\
\text { instrumentation cases } \quad 1 \text { IV Cefuroxime for } 24 \text { hours }\end{array}$ \\
\hline
\end{tabular}

\section{TABLE 1: Standard and enhanced prophylaxis protocol measures}

Comparison of the standard protocol versus enhanced protocol. Dosage and administration of antibiotics were calculated based on patient's weight and renal clearance. Standard doses were not used.

1. Two isopropyl alcohol wipes swabbed over incision site and immediate surrounding regions six times. 2. Betadine ointment applied to incision site and immediate surrounding region after use of alcohol wipes. Only used in skin preparation, not after closure. 3 . Drains were removed when output reached $<30 \mathrm{cc} /$ eight hour shift. 4 . Drains used regularly for instrumented cases and selectively for noninstrumented cases. 


\section{Cureus}

\begin{tabular}{|c|c|c|}
\hline Indication & Superficial Incisional SSI Criteria & Deep Incisional SSI Criteria \\
\hline Timeline & $\begin{array}{l}\text { MUST occur within } 30 \text { days after } \\
\text { operative procedure }\end{array}$ & $\begin{array}{l}\text { MUST occur within: } 30 \text { days of operative procedure if NO implant left } \\
\text { in place One year if implant left in place }\end{array}$ \\
\hline $\begin{array}{l}\text { Tissue } \\
\text { Involvement }\end{array}$ & $\begin{array}{l}\text { MUST involve only skin and } \\
\text { subcutaneous tissue of the incision }\end{array}$ & $\begin{array}{l}\text { MUST involve deep soft tissues (fascial and muscle layers) of the } \\
\text { incision }\end{array}$ \\
\hline $\begin{array}{l}\text { Drainage, } \\
\text { Culture, } \\
\text { Symptoms }\end{array}$ & $\begin{array}{l}\text { At least one of the following: } \\
\text { Purulent drainage from incision } \\
\text { Organisms isolated from aseptically } \\
\text { obtained culture At least one of the } \\
\text { following signs or symptoms of } \\
\text { infection and the superficial incision } \\
\text { Pain Redness Tenderness } \\
\text { Localized swelling Heat }\end{array}$ & $\begin{array}{l}\text { At least one of the following: Purulent drainage from the deep } \\
\text { incision but not the organ space component Deep incision } \\
\text { spontaneously dehisces or is deliberately opened by the surgeon } \\
\text { and is culture positive OR not cultured when the patient has at least } \\
\text { one of the following: Fever Localized pain Tenderness } 3 \text { ) An abscess } \\
\text { or other evidence of infection involving the deep incision found on } \\
\text { direct examination, during reoperation, or by histopathologic or } \\
\text { radiologic exam }\end{array}$ \\
\hline
\end{tabular}

Diagnosis By surgeon or attending physician By surgeon or attending physician

\section{TABLE 2: Centers for Disease Control and Prevention (CDC) Surgical site infection (SSI) definitions}

Definition of superficial and deep incisional SSI criteria based on Centers for Disease Control and Prevention[20].

Data collection consisted of a retrospective review of a patient database of all spinal procedures performed by the senior author drawn from medical records, anesthesia reports, and operative reports. Demographic data included age, sex, body mass index (BMI), American Society of Anesthesiologists (ASA) physical status and length of surgery. These characteristics were chosen for general comparison of the patients under the standard or enhanced protocols and were all measured and recorded from medical and anesthesia records. Cervical, thoracic, and lumbar distinctions as well surgical approach were all defined by the operative location on the patient's spine. The primary outcome variable evaluated was the incidence of surgical site infection, which was defined as per CDC standards and confirmed with wound cultures. All data were collected and analyzed by independent reviewers uninvolved in the surgical treatment of the patient's study. Statistical analysis involved two-tailed Fisher's exact tests. Significance was defined using a p-value of less than 0.05 . The institutional review board granted approval for this study with waiver of patient consent.

\section{Results}

Over this time frame, a total of 1486 patients met our criteria for inclusion. Table 3 reflects that the patients under the enhanced protocol tend to be older, female and have a slightly higher (BMI/ASA) score compared to the standard protocol group. Table 4 reflects the number of spine surgeries by operative region (cervical, thoracic, and lumbar) and the breakdown of these categories under the use of the standard and enhanced protocols. A total of nine cases ( $\mathrm{n}=$ nine) met the criteria for SSI as indicated by the criteria set by the CDC (Table 2) for an overall $0.61 \%$ infection rate across all spinal surgeries. All cases of SSI occurred under the standard protocol. Of the nine total cases, we observed four cervical, two thoracic, and three lumbar cases of SSI during this time frame. No further cases of SSI were observed during the utilization of the enhanced protocol, with a decline in infection rate from $2.28 \%$ under the standard protocol to 


\section{Cureus}

zero percent under the enhanced protocol ( $\mathrm{p}<0.0001)$. Likewise, the infection rates declined to zero in each operative region under the enhanced protocol, with infection rates under the standard protocol of $2.44 \%, 3.51 \%$ and $1.73 \%$ of cervical, thoracic, and lumbar patients, respectively ( $\mathrm{p}=0.0030, \mathrm{p}=0.1487, \mathrm{p}=0.0192$, respectively). Statistical significance was thus established for overall spine surgery as well as for cervical and lumbar spine surgery. The incidence of SSI was significantly reduced with the use of the enhanced protocol.

\begin{tabular}{|c|c|c|}
\hline & Standard Protocol $(n=394)$ & Enhanced Protocol $(n=1092)$ \\
\hline Mean Age (years) & $51.2 \pm 16.2$ & $56.9 \pm 14.4$ \\
\hline$\%$ Male & 57.9 & 50.6 \\
\hline Mean BMI & $26.88 \pm 5.11$ & $27.65 \pm 5.61$ \\
\hline Mean ASA Status & $2.42 \pm 0.74$ & $2.54 \pm 0.68$ \\
\hline Surgery Length (hours) & $4.17 \pm 2.02$ & $4.23 \pm 1.86$ \\
\hline
\end{tabular}

\section{TABLE 3: Patient demographics}

Patient demographics of both cohorts demonstrating similar mean age, percent of male patients, mean body mass index, mean American Society of Anesthesiologist physical status classification and length of surgery.

\begin{tabular}{|l|llllll|}
\hline & \multicolumn{2}{l}{ Standard Protocol } & \multicolumn{2}{l|}{ Enhanced Protocol } & \multicolumn{2}{l|}{ Total } \\
\hline Operative Region & Cases (\% Total) & Infections $(\%)$ & Cases $(\%$ Total) & Infections (\%) & Cases (\% Total) & Infections (\%) \\
Cervical & $164(41.6)$ & $4(2.44)$ & $532(48.7)$ & 0 & $696(46.8)$ & $4(0.57)$ \\
Thoracic & $57(14.5)$ & $2(3.51)$ & $90(8.3)$ & 0 & $147(9.9)$ & $2(1.36)$ \\
Lumbar & $173(43.9)$ & $3(1.73)$ & $470(43.0)$ & 0 & $643(43.4)$ & $3(0.47)$ \\
Total & $394(100)$ & $9(2.28)$ & $1092(100)$ & 0 & $1486(100)$ & $9(0.61)$ \\
\hline
\end{tabular}

\section{TABLE 4: Incidence of surgical site infections by operative region of the spine}

Incidence of surgical site infections by operative region of the spine shows that the majority of cases were cervical site infections. After the institution of the enhanced protocol, no further surgical site infections were observed.

In addition, all SSI in this study occurred under posterior operative approaches under the standard protocol (Table 5). Table 5 presents the total number of spine surgeries performed under posterior approaches $(\mathrm{n}=924)$ and the number of posterior-approach spine surgeries by operative region (cervical, thoracic, and lumbar). Two hundred and thirty-nine posterior surgeries were performed under the standard protocol, and 685 posterior surgeries were performed under the enhanced protocol. The total infection rate with a posterior approach declined from $3.77 \%$ to zero percent $(\mathrm{p}<0.0001)$. As above, the infection rates of cervical, thoracic, and lumbar surgeries performed under a posterior approach all declined to zero from 


\section{Cureus}

$5.63 \%, 4.44 \%$, and $2.44 \%$, respectively ( $\mathrm{p}=0.0042, \mathrm{p}=0.1510, \mathrm{p}=0.0119$, respectively). Cervical, lumbar and total surgeries performed under posterior approaches all reached statistical significance. Thus, the enhanced protocol greatly reduced the incidence of SSI as compared to that under the standard protocol.

\begin{tabular}{|l|lllllll||}
\hline \multicolumn{7}{|l}{ Standard Protocol } & \multicolumn{2}{l|}{ Enhanced Protocol } & Total & \\
\hline $\begin{array}{l}\text { Operative } \\
\text { Region }\end{array}$ & $\begin{array}{l}\text { Cases }(\% \\
\text { Total })\end{array}$ & $\begin{array}{l}\text { Infections } \\
(\%)\end{array}$ & $\begin{array}{l}\text { Cases }(\% \\
\text { Total })\end{array}$ & $\begin{array}{l}\text { Infections } \\
(\%)\end{array}$ & $\begin{array}{l}\text { Cases }(\% \\
\text { Total })\end{array}$ & $\begin{array}{l}\text { Infections } \\
(\%)\end{array}$ & P-value \\
Cervical & $71(29.7)$ & $4(5.63)$ & $203(29.6)$ & 0 & $274(29.7)$ & $4(1.46)$ & 0.0042 \\
Thoracic & $45(18.8)$ & $2(4.44)$ & $70(10.2)$ & 0 & $115(12.4)$ & $2(1.74)$ & 0.1510 \\
Lumbar & $123(51.5)$ & $3(2.44)$ & $412(60.2)$ & 0 & $535(57.9)$ & $3(0.56)$ & 0.0119 \\
Total & $239(100)$ & $9(3.77)$ & $685(100)$ & 0 & $924(100)$ & $9(0.97)$ & 0.0001 \\
\hline
\end{tabular}

\section{TABLE 5: Incidence of surgical site infections by operative region on a posterior approach}

All cases of surgical site infections were observed using a posterior operative approach. No further cases of SSI were observed after the institution of the enhanced protocol $(p<0.0001)$ across all regions of the spine. However, statistical significance was reached only for cervical and lumbar cases $(p<0.0042$ and $p<0.0119$, respectively).

Table 6 displays the microbiology of the surgical wound cultures of all nine cases of SSI, as required by the CDC guidelines. Six of the nine patients and each of the three lumbar and two thoracic patients - with SSI grew methicillin-resistant Staphylococcus aureus from their surgical wound sites. A Staphylococcus species was present in each surgical wound culture with varying degrees of antibiotic susceptibility and coagulase production. 


\section{Cureus}

\begin{tabular}{|c|c|c|}
\hline Case & Operative Region & Organisms Detected \\
\hline 1 & Cervical & Methicillin-resistant Staphylococcus aureus \\
\hline 2 & Cervical & Methicillin-susceptible Staphylococcus aureus \\
\hline 3 & Cervical & Coagulase-negative Staphylococcus Escherichia coli \\
\hline 4 & Cervical & Coagulase-negative Staphylococcus Pseudomonas aeruginosa Staphylococcus epidermidis \\
\hline 5 & Thoracic & Methicillin-resistant Staphylococcus aureus Staphylococcus epidermidis \\
\hline 6 & Thoracic & Methicillin-resistant Staphylococcus aureus \\
\hline 7 & Lumbar & Methicillin-resistant Staphylococcus aureus \\
\hline 8 & Lumbar & Methicillin-resistant Staphylococcus aureus \\
\hline 9 & Lumbar & Methicillin-resistant Staphylococcus aureus \\
\hline
\end{tabular}

\section{TABLE 6: Surgical wound culture microbiology}

Six of the nine surgical site infections contained methicillin-resistant Staphylococcus aureus.

\section{Discussion}

In this study, the incidence of SSI was significantly reduced following the implementation of an enhanced anti-infection protocol. This is supported by the reduced infection rate to zero percent under the enhanced protocol until the end of the patient data query (March 2014). Similar reductions in SSI rates have been observed in several other studies in which protocol modifications were employed [21-23]. However, some studies have suggested that the general incidence of SSI has not substantially decreased in recent years, despite the introduction of evidence-based guidelines for SSI prevention such as the Surgical Care Improvement Project (SCIP) [24-25]. Such findings contrast with the present study, and the results stand to support the implementation of, and compliance with, and evidence-based approach to anti-infection protocols.

Not only does this study support the introduction of more advanced prophylaxis protocols, but it also substantiates the established finding that SSI is more common following posterior spine procedures compared to anterior approaches. No case of SSI was observed in anterior approaches, regardless of protocol. All nine SSIs occurred after posterior procedures. The observed reduction in SSI in posterior approaches supports our claim that stringent use of this anti-infection protocol reduced the rate in these surgeries. The study, however, was not powered appropriately to determine which operative region of posterior approaches presented the greatest risk of postoperative infection. This underscores the need to understand the incidence of SSI in the context of the given risk factors for the particular procedure involved.

Identifying patient specific pre-operative risk factors are essential for future research to develop an evidence-based approach to SSI. The multifaceted nature of this changed and enhanced protocol hinders our ability to derive which component contributed most substantially to the reduced infection rate. Evidence suggests that multiple of the enhancements may affect the prevention of SSI, from preoperative skin preparation protocol to irrigation to antibiotic usage 
$[14,15,21,22,26-28]$. Future studies should include analysis by type of surgery and indication for surgery.

In addition, as a retrospective review, the validity of our study rests primarily on the quality and nature of the data collection. The database utilized for this study, however, was produced and analyzed by independent reviewers uninvolved in the surgical treatment of the study's patients and thus unbiased toward the results.

\section{Conclusions}

An evidence-based understanding of patient-specific and procedure-specific risk factors, as well as specific facets of the protocol itself, remains to be seen. Additional analyses are warranted to quantitatively analyze patient comorbid factors and procedure characteristics to develop an algorithm to predict the relative risk of infection for any given patient. Further investigation is needed to compare the results with patient outcomes in other practices within the neurosurgery department and with other institutions. With this in mind, we recommend future study and appropriate use of this enhanced protocol.

\section{Additional Information \\ Disclosures}

Human subjects: Consent was obtained by all participants in this study. issued approval 1300952. Animal subjects: All authors have confirmed that this study did not involve animal subjects or tissue. Conflicts of interest: In compliance with the ICMJE uniform disclosure form, all authors declare the following: Payment/services info: All authors have declared that no financial support was received from any organization for the submitted work. Financial relationships: All authors have declared that they have no financial relationships at present or within the previous three years with any organizations that might have an interest in the submitted work. Other relationships: All authors have declared that there are no other relationships or activities that could appear to have influenced the submitted work.

\section{References}

1. Abdul-Jabbar A, Berven SH, Hu SS, et al.: Surgical site infections in spine surgery: Identification of microbiologic and surgical characteristics in 239 cases. Spine. 2013, 38:142531. 10.1097/BRS.0b013e3182a42a68

2. Xing D, Ma J, Ma X, Song D, et al.: A methodological, systematic review of evidence-based independent risk factors for surgical site infections after spinal surgery. Eur Spine J. 2013, 22:605-15. 10.1007/s00586-012-2514-6

3. Bekelis K, Desai A, Bakhoum SF, et al.: A predictive model of complications after spine surgery: the National Surgical Quality Improvement Program (NSQIP) 2005-2010. Spine J. 2014, 14:1247-1255 . 10.1016/j.spinee.2013.08.009

4. Chaichana KL, Bydon M, Santiago-Diepa DR, et al.: Risk of infection following posterior instrumented lumbar fusion for degenerative spine disease in 817 consecutive cases. J Neurosurg Spine. 2014, 20:45-52. 10.3171/2013.10.SPINE1364

5. Chikawa T, Sakai T, Bhatia NN, et al.: Retrospective study of deep surgical site infections following spinal surgery and the effectiveness of continuous irrigation. Br J Neurosurg. 2011, 25:621-4. 10.3109/02688697.2010.546902

6. Marquez-Lara A, Nandyala SV, Sankaranarayanan S, et al.: Body mass index as a predictor of complications and mortality after lumbar spine surgery. Spine. 2014, 39:798-804.

10.1097/BRS.0000000000000232

7. Pull ter Gunn AF, Cohen DB: Incidence, prevalence, and analysis of risk factors for surgical site infection following adult spinal surgery. Spine. 2009, 34:1422-8. 10.1097/BRS.0b013e3181a03013

8. Veeravagu A, Patil CG, Lad SP, Boakye M: Risk factors for postoperative spinal wound 
infections after spinal decompression and fusion surgeries. Spine. 2009, 34:1869-72.

10.1097/BRS.0b013e3181adc989

9. Calderone RR, Garland DE, Capen DA, et al.: Cost of medical care for post-operative spinal infections. Orthop Clin North Am. 1996, 27:171-82.

10. Cronquist AB, Jakob K, Lai L, Della Latta P, et al.: Relationship between skin microbial counts and surgical site infection after neurosurgery. Clin Infect Dis. 2001, 33:1302-8.

$10.1086 / 322661$

11. Kirkland KB, Briggs JP, Trivette SL, et al.: The impact of surgical-site infections in the 1990s: attributable mortality, excess length of hospitalization, and extra costs. Infect Control Hosp Epidemiol. 1999, 20:725-30.

12. Levi AD, Dickman CA, Sonntag VK: Management of postoperative infections after spinal instrumentation. J Neurosurg Spine. 1997, 86:975-80. 10.3171/jns.1997.86.6.0975

13. Olsen MA, Mayfield J, Lauryssen C, et al.: Risk factors for surgical site infection in spinal surgery. J Neurosurg Spine. 2003, 98:149-55.

14. Emohare O, Ledonio CG, Hill BW, et al.: Cost savings analysis of intrawound vancomycin powder in posterior spinal surgery. Spine J. 2014, 14:2710-2715. 10.1016/j.spinee.2014.03.011

15. Ghobrial GM, Thakkar V, Andrews E, et al.: Intraoperative vancomycin use in spinal surgery . Spine. 2014, 39:550-5. 10.1097/BRS.0000000000000241

16. Hill BW, Emohare O, Song B, et al.: The use of vancomycin powder reduces surgical reoperation in posterior instrumented and noninstrumented spinal surgery. Acta Neurochir. 2014, 156:749-54. 10.1007/s00701-014-2022-z

17. Tubaki VR, Rajasekaran S, Shetty AP: Effects of using intravenous antibiotic only versus local intrawound vancomycin antibiotic powder application in addition to intravenous antibiotics on postoperative infection in spine surgery in 907 patients. Spine. 2013, 38:2149-55. 10.1097/BRS.0000000000000015

18. McGirt JM, Parker SL, Lerner J, et al.: Comparative analysis of perioperative surgical site infection after minimally invasive versus open posterior/transforaminal lumbar interbody fusion: analysis of hospital billing and discharge data from 5170 patients. J Neurosurg Spine. 2011, 14:771-8. 10.3171/2011.1.SPINE10571

19. Mujagic E, Zwimpfer T, Marti WR, et al.: Evaluating the optimal timing of surgical antimicrobial prophylaxis: study protocol for a randomized controlled trial. Trials. 2014, 15:188. 10.1186/1745-6215-15-188

20. Horan TC, Andrus M, Dudeck MA: CDC/NHSH surveillance definition of health careassociated infection and criteria for specific types of infections in the acute care setting. Am J Infect Control. 2008, 36:309-32. 10.1016/j.ajic.2008.03.002

21. Godil SS, Parker SL, O’Neill KR, et al.: Comparative effectiveness and cost-benefit analysis of local application of vancomycin powder in posterior spinal fusion for spine trauma. J Neurosurg Spine. 2013, 19:331-5. 10.3171/2013.6.SPINE121105

22. Pahys JM, Pahys JR, Cho SK, et al.: Methods to decrease postoperative infections following posterior cervical spine surgery. J Bone Joint Surg Am. 2013, 95:549-54. 10.2106/JBJS.K.00756

23. Sweet FA, Roh M, Sliva C: Intrawound application of vancomycin for prophylaxis in instrumented thoracolumbar fusions: efficacy, drug levels, and patient outcomes. Spine. 2011, 36:2084-8. 10.1097/BRS.0b013e3181ff2cb1

24. Hawn MT, Vick CC, Richman J, et al.: Surgical site infection prevention: time to move beyond the surgical care improvement program. Ann Surg. 2011, 254:494-9.

10.1097/SLA.0b013e31822c6929

25. Leaper DJ, Tanner J, Kiernan M, et al.: Surgical site infection: poor compliance with guidelines and care bundles. Int Wound J. 2015, 12:357-62. 10.1111/iwj.12243

26. Kim BD, Hsu WK, De Oliveira GS, et al.: Operative duration as an independent risk factor for postoperative complications in single-level lumbar fusion:an analysis of 4588 surgical cases. Spine. 2014, 39:510-20. 10.1097/BRS.0000000000000163

27. Watanabe M, Sakai D, Matsuyama D, et al.: Risk factors for surgical site infection following spine surgery: efficacy of intraoperative saline irrigation. J Neursosurg Spine. 2010, 12:540-6. 10.3171/2009.11.SPINE09308

28. Dumville JC, McFarlane E, Edwards P, et al.: Preoperative skin antiseptics for preventing surgical wound infections after clean surgery. Cochrane Database Syst Rev. 2013, 28:10.1002/14651858.CD003949.pub3 